\title{
Volker Leppin, Die fremde Reformation. Luthers mystische Wurzeln
}

\section{Gérald Chaix}

\section{OpenEdition}

\section{Journals}

Édition électronique

URL : http://journals.openedition.org/ifha/9146

DOl : $10.4000 /$ ifha. 9146

ISSN : 2198-8943

\section{Éditeur}

IFRA - Institut franco-allemand (sciences historiques et sociales)

\section{Référence électronique}

Gérald Chaix, «Volker Leppin, Die fremde Reformation. Luthers mystische Wurzeln », Revue de I'IFHA [En ligne], Date de recension, mis en ligne le 14 juin 2018, consulté le 24 septembre 2020. URL : http:// journals.openedition.org/ifha/9146; DOI : https://doi.org/10.4000/ifha.9146

Ce document a été généré automatiquement le 24 septembre 2020

(CIFHA 
Volker Leppin, Die fremde Reformation. Luthers mystische Wurzeln

Gérald Chaix

\section{RÉFÉRENCE}

Volker Leppin, Die fremde Reformation. Luthers mystische Wurzeln, München: C.H. Beck, 2016, 247 p., 21,95€ 
Dans un premier temps, Volker Leppin brosse le tableau de la piété du Moyen Âge tardif. Au-delà de sa propre expérience, Luther la connaît par l'intermédiaire de son supérieur et confesseur, Johann von Staupitz, par sa lecture et son édition de la Théologie allemande de Johannes Tauler, mais aussi par sa propre réflexion sur les notions de pénitence, de repentir et d'indulgence (dont ne se satisfait précisément pas Tauler!). Il étudie ensuite le cheminement qui conduit de la théologie mystique aux 95 thèses de 1517. Ce cheminement réunit Staupitz, dont les prédications pour l'Avent de 1517 sont publiées et traduites en allemand à Nuremberg, Luther et leur confrère Kaspar Güttel, dont les sermons pour le Carême de 1518 sont publiés la même année à Leipzig. On remarque le rôle de

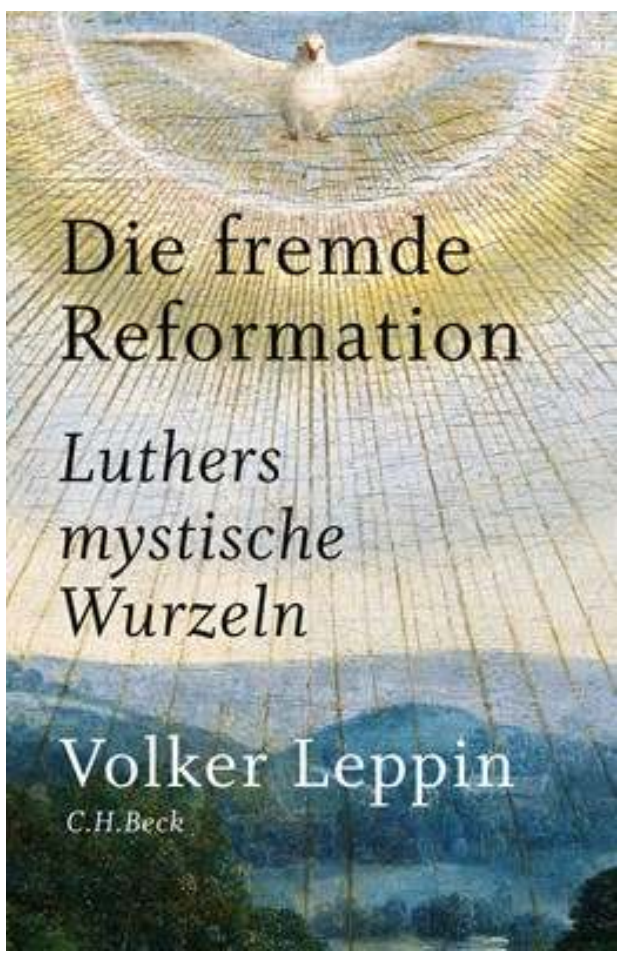
plaque tournante joué par Nuremberg et l'importance du réseau qui y gravite autour du juriste et humaniste Christophe Scheurl. Celui-ci fait le lien entre les Augustins, Staupitz et Luther, et Johann Eck, auquel il indique les évolutions perceptibles à Wittenberg dans une lettre datée du 14 janvier 1517. Les thèses de 1517 reflètent cette influence de la théologie mystique. Ce qui est neuf avec Luther, c'est la rigueur - qu'il doit à l'humanisme - avec laquelle il développe ses thèses. Dans les thèses d'octobre se rejoignent deux débats médiévaux : celui sur la piété pénitentielle intérieure, celui sur « la comptabilité de l'au-delà » et la place des indulgences.

Le chapitre suivant fait passer de la réforme à la critique de l'Église. Celle-ci s'exprime dans la correspondance. Par ailleurs, échappant largement à Luther, elle se diffuse et s'amplifie par le jeu des impressions et des traductions. Très vite, le sujet va être non seulement celui de la vérité et des "autorités" mais aussi celui de la primauté pontificale. Luther n'est plus simplement l'auteur d'écrits édifiants. Il est engagé dans le combat pour la bonne cause. Un public se constitue, même si le recours aux disputes académiques reste privilégié. Celle tenue à Heidelberg, à la faculté des Arts, en 1518, est à l'initiative des Augustins. Celle tenue à Leipzig, dans une salle du château ducal, en 1519, est organisée par l'université de Leipzig et oppose Johann Eck à Andreas Karlstadt et Martin Luther. Toutes se déroulent en latin, mais leur caractère public leur assure une médiatisation que complètent et amplifient les relations imprimées qui en sont immédiatement établies. Dès 1518, en marge de la diète d'Augsbourg, la rencontre de Luther avec le cardinal Cajetan avait mis en évidence les enjeux politiques et ecclésiologiques de ces débats publics. L'autorité de l'Écriture et son interprétation sont au cœur des débats. L'édifice ecclésial est directement mis en cause. La polarisation est alors éclatante: Luther est devenu un hérétique, le pape l'Antéchrist. C'est une situation à laquelle Luther n'était pas vraiment préparé. Assez rapidement, ce dernier va faire de l'Écriture la seule autorité. Dans la foulée, la diète de Worms aboutit, en 1521, à ce que Luther lui-même a appelé sa " troisième excommunication » : la mise 
au ban de l'Empire, succédant à la décision de Staupitz de le relever de son devoir d'obéissance, pour ne pas avoir à le sanctionner, puis à l'excommunication pontificale. Le théologien rebelle est devenu un martyr potentiel. Un processus de personnalisation et d'héroïsation s'enclenche. Hans Holbein grave Luther en Hercules germanicus. Ce qui est peut-être, pour le Bâlois proche des milieux érasmiens, une manière implicite de critiquer une fougue jugée excessive. Aux yeux du monde, Luther apparaît comme un rebelle. Lui a foi en Dieu, le maître du monde. Il s'éloigne progressivement de la théologie mystique et privilégie le retour à l'Écriture. Il est ainsi l'héritier du solus Christus de Staupitz, du sola gratia d'Augustin, du sola scriptura formulé par Melanchthon dans sa thèse le 9 septembre 1519. Quant au sola fide, il l'invoque dans le Sermo de triplici iustitia, au début de l'année 1518.

Loin de provoquer une rupture brutale, Luther procède par association. À cet égard, $L a$ Liberté $d u$ chrétien résume bien sa position. L'ouvrage est à la fois mystique et réformateur. La conception du sacerdoce universel est très proche de celle de Tauler, mais Luther va plus loin en l'étendant à tous les croyants, autrement dit tous les baptisés. Il est proche également de Staupitz pour ce qui concerne les rapports de l'âme et du Christ ainsi que la problématique des fiançailles spirituelles. Même dans la célèbre affirmation de Luther à Worms, selon laquelle il n'est pas possible d'agir contre sa conscience, V. Leppin veut voir une influence mystique. Le chemin est alors libre, cinquième étape, pour passer de la mystique à la politique. En témoignent l'appel À la noblesse chrétienne de la nation allemande, mais aussi le texte intitulé Tessaradecas qu'il écrit durant l'été 1519 à l'intention de l'Électeur de Saxe, alors malade, auquel il rappelle que le Christ est la seule consolation. En témoigne aussi le Sermon sur les bonnes œuvres, d'ailleurs dédié à Johann, le frère de l'Électeur, avec lequel celui-ci partage l'administration de l'électorat. Élaborée à partir de la théologie mystique, la notion de justification par la foi est clairement "recentrée » (B. Hamm). Luther peut à présent développer sa conception politique. Au XIX siècle, on lui donnera le nom de «théorie des deux règnes ». Il y reprend la distinction augustinienne entre la cité de Dieu et la cité des hommes. Il en tire l'opposition entre deux formes de gouvernance: celle, séculière, qui réclame l'obéissance, limitée cependant par les exigences de la " conscience ", comme il l'a déjà affirmé à Worms ; celle, spirituelle, qui s'appuie sur la prédication de l'Évangile. C'est cette distinction qui fonde son attitude durant les soulèvements paysans. Pour Luther, l'attitude de ces derniers est trop « charnelle ». Sa propre perspective reste, elle, «mystique ». Luther lui-même, dernière étape, ne rompt totalement avec la vie monacale qu'en $1524 / 25$, abandonnant son froc dans un premier temps (octobre 1524) et, surtout, décidant de se marier dans un deuxième temps (juin 1525). Les débats qui l'opposent au même moment aux Schwärmer lui donnent l'occasion de revenir aux questions de la théologie mystique et notamment à celle de l'« inspiration » pour s'en éloigner définitivement. 
INDEX

Index chronologique : Période moderne

Thèmes : Histoire religieuse ; Histoire des mentalités

\section{AUTEURS}

GÉRALD CHAIX

Université de Tours, UMR 7323 